\title{
Hybrid Biosynthetic Autograft Extender for Use in Posterior Lumbar Interbody Fusion: Safety and Clinical Effectiveness
}

\author{
Mokbel K. Chedid ${ }^{1}$, Kelly M. Tundo ${ }^{1}$, Jon E. Block ${ }^{2}$ and Jeffrey M. Muir ${ }^{*}, 2$ \\ ${ }^{1}$ Henry Ford Health System - West Bloomfield Michigan, 6777 West Maple Road, West Bloomfield, MI 48322, USA \\ ${ }^{2}$ The Jon Block Group, 2210 Jackson Street, Suite 401, San Francisco, CA 94115, USA
}

\begin{abstract}
Autologous iliac crest bone graft is the preferred option for spinal fusion, but the morbidity associated with bone harvest and the need for graft augmentation in more demanding cases necessitates combining local bone with bone substitutes. The purpose of this study was to document the clinical effectiveness and safety of a novel hybrid biosynthetic scaffold material consisting of poly(D,L-lactide-co-glycolide) (PLGA, 75:25) combined by lyophilization with unmodified high molecular weight hyaluronic acid (10-12\% wt:wt) as an extender for a broad range of spinal fusion procedures. We retrospectively evaluated all patients undergoing single- and multi-level posterior lumbar interbody fusion at an academic medical center over a 3-year period. A total of 108 patients underwent 109 procedures (245 individual vertebral levels). Patient-related outcomes included pain measured on a Visual Analog Scale. Radiographic outcomes were assessed at 6 weeks, 3-6 months, and 1 year postoperatively. Radiographic fusion or progression of fusion was documented in 221 of 236 index levels $(93.6 \%)$ at a mean $( \pm \mathrm{SD})$ time to fusion of $10.2+4.1$ months. Single and multilevel fusions were not associated with significantly different success rates. Mean pain scores ( $+\mathrm{SD})$ for all patients improved from $6.8+2.5$ at baseline to $3.6+2.9$ at approximately 12 months. Improvements in VAS were greatest in patients undergoing one- or two-level fusion, with patients undergoing multi-level fusion demonstrating lesser but still statistically significant improvements. Overall, stable fusion was observed in $64.8 \%$ of vertebral levels; partial fusion was demonstrated in $28.8 \%$ of vertebral levels. Only 15 of 236 levels $(6.4 \%)$ were non-fused at final follow-up.
\end{abstract}

Keywords: Bone extender, hyaluronic acid, intervertebral level, local bone autograft, lumbar fusion.

\section{INTRODUCTION}

With increasing understanding of the biological and biomechanical basis of bone fusion, the quest for better and more efficient bone fusion technologies in spinal surgery continues. While autologous iliac crest bone is recognized as the most successful grafting material due to its osteoconductive, osteogenic and osteoinductive properties [1,2], complication rates of this invasive procedure remain high [3-5], with protracted postoperative pain at the donor site being the most commonly reported complication [6]. In an attempt to limit such complications by either reducing or eliminating iliac crest autograft harvest, demineralized bone matrix (DBM) and synthetic osteoconductive bone graft extenders (BGEs) are often used in spinal fusion procedures as an adjunct to patient-derived autograft [7-11]. Similarly, local bone may be used in lieu of iliac crest grafts, although current evidence suggests that while local bone is equally effective as iliac crest bone in single-level fusion $[6,12]$, it has been associated with significantly lower fusion rates when utilized in multi-level fusion due to volume limitations [1].

A number of bone graft substitutes are available, the most common of which are ceramic- or calcium-phosphate-

*Address correspondence to this author at the Jon Block Group, 2210 Jackson St., Suite 401, San Francisco, CA 94115, USA;

Tel: 905-962-6362; Fax: 905-304-9413; E-mail: drjeffmuir@gmail.com based synthetic materials. While these products provide a suitable scaffolding upon which to build new bone, they are inherently unable to stimulate bone growth without the patient's own bone or marrow to augment the process. Alternate options such as tricalcium phosphate, calcium sulfate and hydroxyapatite, while possessing osteoconductive properties, are associated with equivocal results regarding fusion rates [13]. To address the shortcomings of the currently available technology, a fully-resorbable hybrid biosynthetic autograft extender for use in spinal fusion was developed (InQu ${ }^{\mathbb{B}}$, ISTO Technologies, Inc., St. Louis, MO). This extender, which has been commercially available since 2008, contains no ceramic component and no animal-derived protein. Instead, it consists of poly(D,L-lactide-co-glycolide) (PLGA, 75:25) combined by lyophilization with unmodified high molecular weight hyaluronic acid (10-12\% wt:wt) to create a hybrid interwoven scaffold. The PLGA component provides compressive resistance to maximize the product's bulking properties. The rate of polymer resorption (3-6 months) is consistent with the rate of bone remodeling at the site of implantation, and this scaffolding support has been shown to direct new bone growth via endochondral ossification $[14,15]$, in contrast to ceramic-based materials, which function through creeping substitution [16].

In order to evaluate the safety and clinical effectiveness of the new hybrid interwoven biosynthetic bone extender, we retrospectively analyzed a consecutive series of posterior lumbar interbody fusion (PLIF) procedures with supplemental instrumentation. 


\section{METHODS}

All patients who underwent elective PLIF procedures at a single academic medical center between March 2008 and March 2011 utilizing the new hybrid interwoven biosynthetic bone extender were included in this analysis. All patients signed an institutional consent form that explained all treatment modalities offered to these patients. No Institutional Review Board (IRB) review was sought as all procedures were performed under our center's standard of care and did not involve any additional research-oriented procedure or products.

One author (MKC) performed a retrospective chart review of eligible patients. The goal of the review and data collection was to document the rate of fusion progression at approximately 18 months of follow-up together with the rate of complications and changes in pain scores and other patient-reported outcomes.

\section{Surgical Procedure}

Surgery was performed using standard surgical techniques of decompression and fusion. In all cases, local bone was harvested during the decompression procedure using an irrigated high speed burr and mucous trap. The harvested bone was combined with concentrated bone marrow aspirate (cBMA) obtained from the posterior iliac crest. In the vast majority of cases $(95 / 109,87 \%)$, the local bone/cBMA mixture was first extended with a cancellous crunch allograft $(5-10 \mathrm{cc})$ before addition of the hybrid interwoven biosynthetic bone extender (5-10 cc). DBM was additionally used in 55 cases $(50 \%)$. The formulation of $\mathrm{InQu}$ (granules or paste mix) was selected for each individual patient based on the amount of bulk necessary to fill the bone void. Nearly all cases $(95 / 109,87 \%)$ used $10 \mathrm{cc}$ of paste mix, while 10 cases $(8.7 \%)$ utilized granules. The formulation used was not recorded in 4 cases.

In all patients, the bone grafting material was placed into the interbody space and the posterolateral gutters as per standard instrumentation procedures. Disc spaces were augmented with $15 \mathrm{cc}$ of bone graft material prior to interbody placement. Interbody cages were used in all cases, with the disc space filled to its entirety. Constructs varied from 1 to 7 intervertebral levels with all cases supported by standard instrumentation (standard rods, screws and when necessary, crosslinks).

\section{Outcomes}

Patient Reported Outcomes - Pain severity were reported subjectively using a visual analog scale (VAS) ranging from 0 (no pain) to 10 (worst pain imaginable). The minimum improvement in VAS required to indicate a minimally clinically important difference (MCID) ranges from 1.3 [17] to 3.0 [18], depending on study and field. For the purposes of this analysis, we set our MCID at an improvement of 2.0 points on the 10-point VAS, which is consistent with similar studies from this field [19-22].

Radiographic Outcomes - Radiographs were obtained at baseline and post-procedure at 6 weeks, 3-6 months, and 12 months; computed tomography (CT) scans were collected 3-
6 months and 12 months post-procedure. Independent boardcertified neuroradiologists reviewed both static and dynamic radiographs and $\mathrm{CT}$ scans to determine fusion status. In all cases, fusion status was defined by the presence of continuous bridging bone between the endplates. Delayed or non-union was characterized by the presence of visualized intervertebral clefts or a vacuum-phenomenon [23]. Fusion was rated as either 0 (non-fusion), 1 (incomplete or progression of fusion) or 2 (stable/solid fusion), with procedures rated either "1" or "2" on this scale deemed to have been successful.

Outcomes for safety were evaluated by recording the nature and frequency of all adverse events that required medical attention or reoperation.

\section{Statistical Analysis}

Alpha was set $a$ priori at 0.05 for all statistical comparisons. Means were compared using Student's t-tests assuming unequal variances and/or single-factor ANOVA. All mean values are presented as mean $\left({ }_{-} \mathrm{SD}\right)$. VAS and VAS responder rates are presented as mean value $(+\mathrm{SD})$.

\section{RESULTS}

One hundred nine (109) procedures were performed on 108 patients involving 245 individual vertebral levels. Patient background characteristics and pre-surgical diagnoses are summarized in Table 1. The mean age was $59.4(+12.4 \mathrm{yrs}$, range $28-85 \mathrm{yrs}) ; 56 \%$ of patients were female. Only 39 patients $(36 \%)$ reported working prior to the surgery. Mean body mass index (BMI) was $30.2( \pm 5.7)$. Mean clinical follow-up was $19.2(+11.7)$ months, while

Table 1. Patient characteristics and diagnosis.

\begin{tabular}{|l|c|}
\hline & All Patients (n=108) \\
\hline \hline Mean age at time of first surgery & $59.4(12.4)($ range: $28-85)$ \\
\hline Gender & \\
\hline Male & $47(44 \%)$ \\
\hline Female & $61(56 \%)$ \\
\hline Mean BMI at time of surgery & $30.2(5.7)$ \\
\hline Diagnosis & \\
\hline Degenerative spinal stenosis & $58(53 \%)$ \\
\hline Degenerative spondylolisthesis & $60(55 \%)$ \\
\hline Non-specific low back pain & $18(17 \%)$ \\
\hline Degenerative scoliosis & $6(6 \%)$ \\
\hline Instability & $3(3 \%)$ \\
\hline Radiculopathy & $4(4 \%)$ \\
\hline Degenerative disc disease & $3(3 \%)$ \\
\hline Post laminectomy syndrome & $1(1 \%)$ \\
\hline
\end{tabular}

mean radiological follow-up was $17.7( \pm 10.4)$ months. Three patients $(2.8 \%)$, accounting for a total of 9 fusion levels, did 
not return for full follow-up. Of the initial 245 levels fused, complete data are available for 236 levels.

PLIF procedures at all 245 levels were instrumented. A detailed summary of the distribution of index levels is provided in Table 2; procedural details are summarized in Table 3. Spinal fusion was performed at a single level in 32 patients $(29.4 \%)$, at two levels in 37 patients $(33.9 \%)$ and at three or more levels in 40 patients $(36.7 \%)$.

Table 2. Details of spine fusion procedure.

\begin{tabular}{|c|c|}
\hline & $\begin{array}{l}\text { All Procedures } \\
\quad(N=109)\end{array}$ \\
\hline \multicolumn{2}{|l|}{ Fusion type } \\
\hline Posterior lumbar interbody fusion (PLIF) & $109(100 \%)$ \\
\hline \multicolumn{2}{|l|}{ Number of operated intervertebral levels } \\
\hline 1 & $32(29.4 \%)$ \\
\hline 2 & $37(33.9 \%)$ \\
\hline 3 & $30(27.5 \%)$ \\
\hline 4 & $6(5.5 \%)$ \\
\hline 5 & $1(0.9 \%)$ \\
\hline 6 & $1(0.9 \%)$ \\
\hline 7 & $2(1.8 \%)$ \\
\hline \multicolumn{2}{|l|}{ Source of bone } \\
\hline Local autograft (bone dust) & $109(100 \%)$ \\
\hline Autologous bone marrow cBMA & $109(100 \%)$ \\
\hline \multicolumn{2}{|l|}{ Extenders } \\
\hline Cancellous allograft extender & $95(87 \%)$ \\
\hline Demineralized bone matrix & $55(50 \%)$ \\
\hline Other (injectable protein polymer formulation *) & $1(1 \%)$ \\
\hline \multicolumn{2}{|l|}{ InQu formulation used } \\
\hline Paste & $95(87 \%)$ \\
\hline Granules & $10(9 \%)$ \\
\hline Not recorded & $4(4 \%)$ \\
\hline
\end{tabular}

\section{Clinical Outcomes, Time to Fusion and Fusion Rate}

Data at final follow-up were available for 236 of 245 individual levels in 105 patients. A total of 221 of 236 vertebral levels $(93.6 \%)$ fulfilled the success criteria for fusion at final follow-up by demonstrating partial or complete fusion (see Table 4). Partial fusion was demonstrated at 68 of 236 fusion levels $(28.8 \%)$ at final follow-up while 153 of 236 levels $(64.8 \%)$ demonstrated complete fusion. Only 15 of 236 levels $(6.4 \%)$ showed no evidence of fusion at final follow-up. The mean time to fusion for the entire group was 10.2 months $(+4.1)$. An example of solid fusion is demonstrated in Fig. (1).

\section{Single-Level Fusion}

Spinal fusion was performed at a single level in 32 patients $(29.4 \%)$. The majority of these procedures $(21)$ were performed at the L4/L5 level, with 4 procedures performed at the L3/L4 level and 7 performed at the L5/S1 level. The mean age of this subgroup was 58.1 yrs $(+14.4)$ with a mean BMI of $28.8( \pm 5.6)$. Mean blood loss in this subgroup was $127 \mathrm{~mL}(+47)$ while mean LOS was 3.7 days $( \pm 1.7)$.

Spinal fusion was rated as successful (complete or partial fusion) in a total of $30(93.8 \%)$ single-level patients. Nonfusion was observed in only $2(6.3 \%)$ patients. Of those patients deemed successfully fused, progression toward or partial fusion was observed in $8(25 \%)$, while 22 patients $(68.8 \%)$ demonstrated stable or complete fusion. The mean time to fusion in this group was 10.7 months $( \pm 3.9)$.

The use of DBM was associated with a higher overall success rate as compared to cases where DBM was not utilized. In cases where DBM was utilized $(n=14), 100 \%$ of patients were found to fulfil the success criteria for fusion, $21 \%(3 / 14)$ of which demonstrated partial fusion and $79 \%$ $(11 / 14)$ demonstrated complete fusion. In contrast, in cases where DBM was not utilized $(n=18), 87 \%$ of patients demonstrated successful fusion, with $28 \%(5 / 18)$ showing partial fusion and $61 \%(11 / 18)$ showing complete fusion. No patients in the group using DBM showed non-fusion at the final follow-up whereas $2(13 \%)$ of those who did not utilize DBM were considered non-fused (see Table 5).

\section{Two-Level Fusion}

A total of 37 patients underwent spinal fusion at two levels. The majority of these procedures (26) were performed between L4 and S1. Ten procedures were performed between L3 and L5, with one procedure occurring between L2 and L4. The mean age of this subgroup was 56.0 yrs $( \pm 11.8)$. Mean blood loss was $230 \mathrm{~mL}( \pm 102)$; mean LOS was 4.2 days $( \pm 1.5)$ and mean BMI was $29.5( \pm 4.6)$.

Table 3. Demographic characteristics sub-grouped based on number of index levels fused.

\begin{tabular}{|c|c|c|c|c|}
\hline & $\begin{array}{c}\text { Single-Level } \\
(\mathrm{n}=\mathbf{3 2} \text { pts, } 32 \text { levels })\end{array}$ & $\begin{array}{c}\text { Two-Level } \\
(\mathrm{n}=37 \mathrm{pts}, 74 \text { levels })\end{array}$ & $\begin{array}{c}\text { Multi-Level } \\
(\mathrm{n}=\mathbf{4 0} \text { pts, } 139 \text { levels })\end{array}$ & $\begin{array}{c}\text { p-Value } \\
\text { (ANOVA) }\end{array}$ \\
\hline Age, mean (SD) & $58.1(14.4)$ & $56.0(11.8)$ & $63.7(10.1)$ & 0.066 \\
\hline BMI, mean (SD) & $28.8(5.6)$ & $29.5(4.6)$ & $39.1(6.4)$ & $0.04^{1}$ \\
\hline Blood loss (mL), mean (SD) & $127(47)$ & $230(102)$ & $426(245)$ & $<0.0001^{2}$ \\
\hline Length of stay (days), mean (SD) & $3.7(1.7)$ & $4.2(1.5)$ & $4.9(2.6)$ & 0.051 \\
\hline
\end{tabular}

${ }^{1}$ Single level $v s$ multi-level comparison: $\mathrm{p}=0.027$. All other paired comparisons: $\mathrm{p}>0.05$.

${ }^{2} \mathrm{p}<0.0001$ for ANOVA and all paired t-tests. 


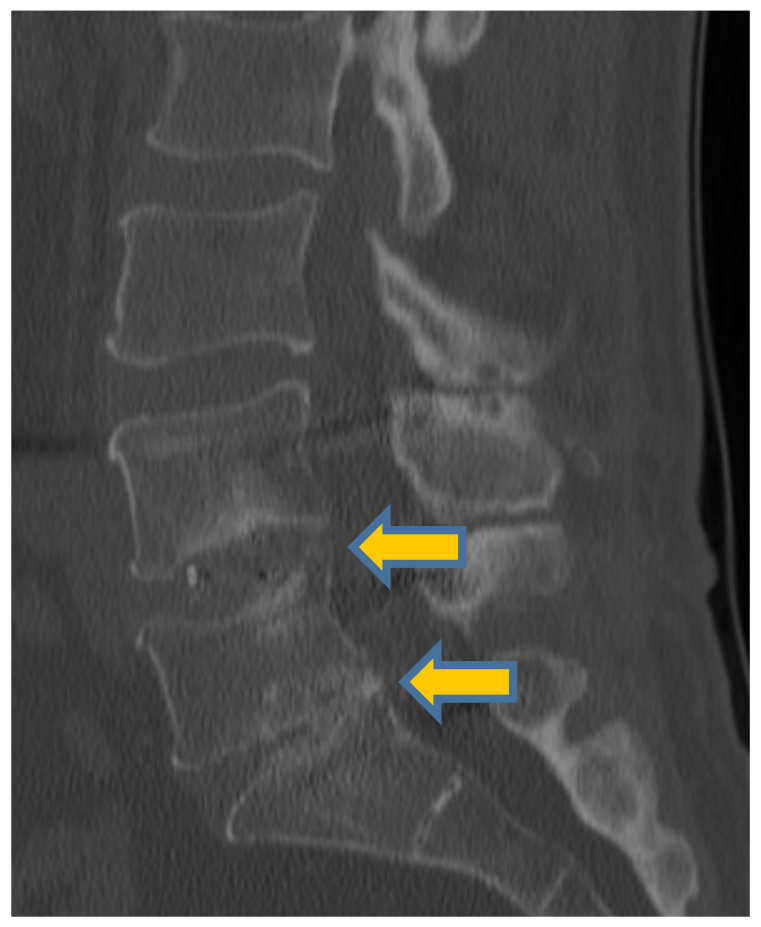

A

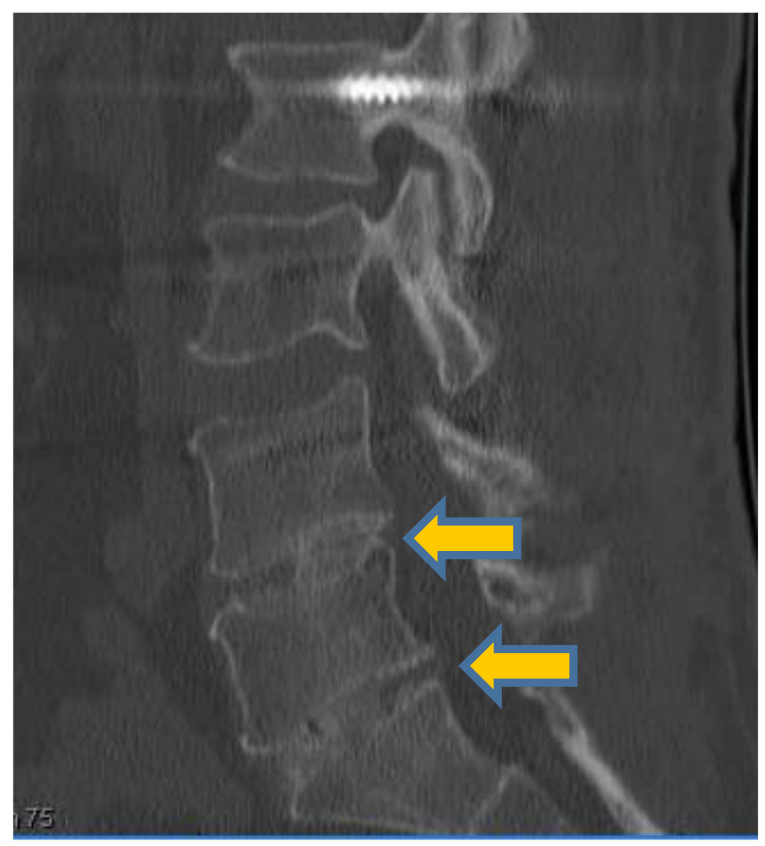

C

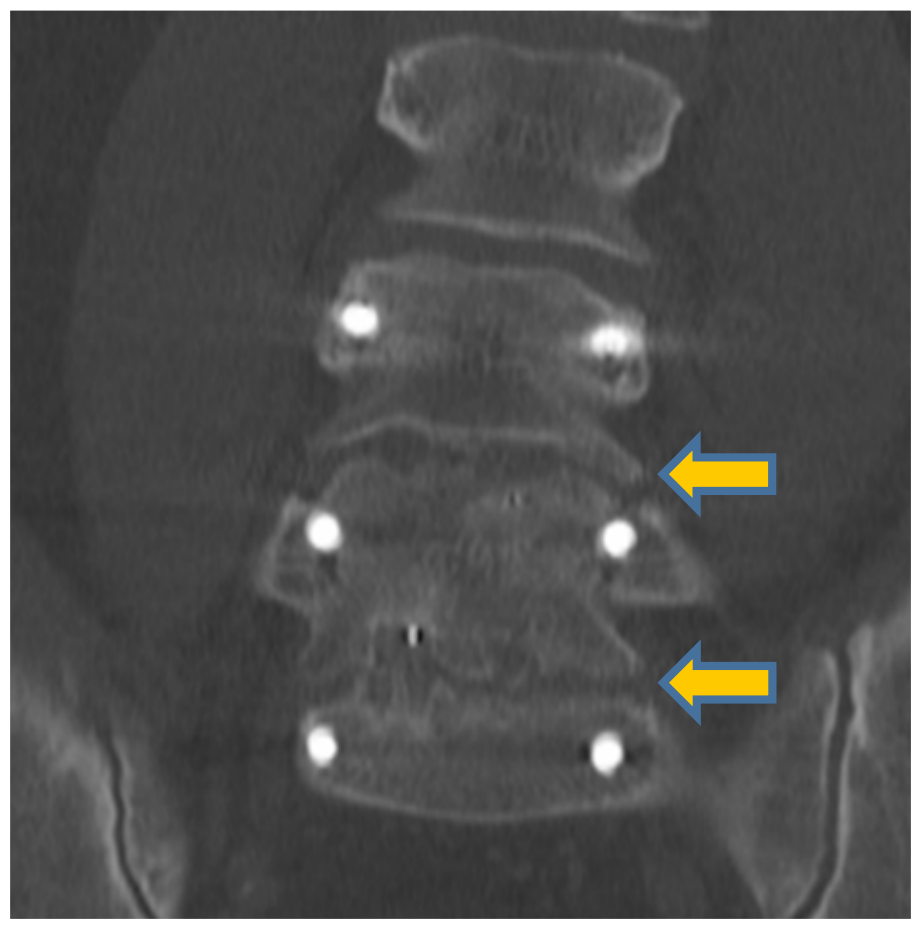

B

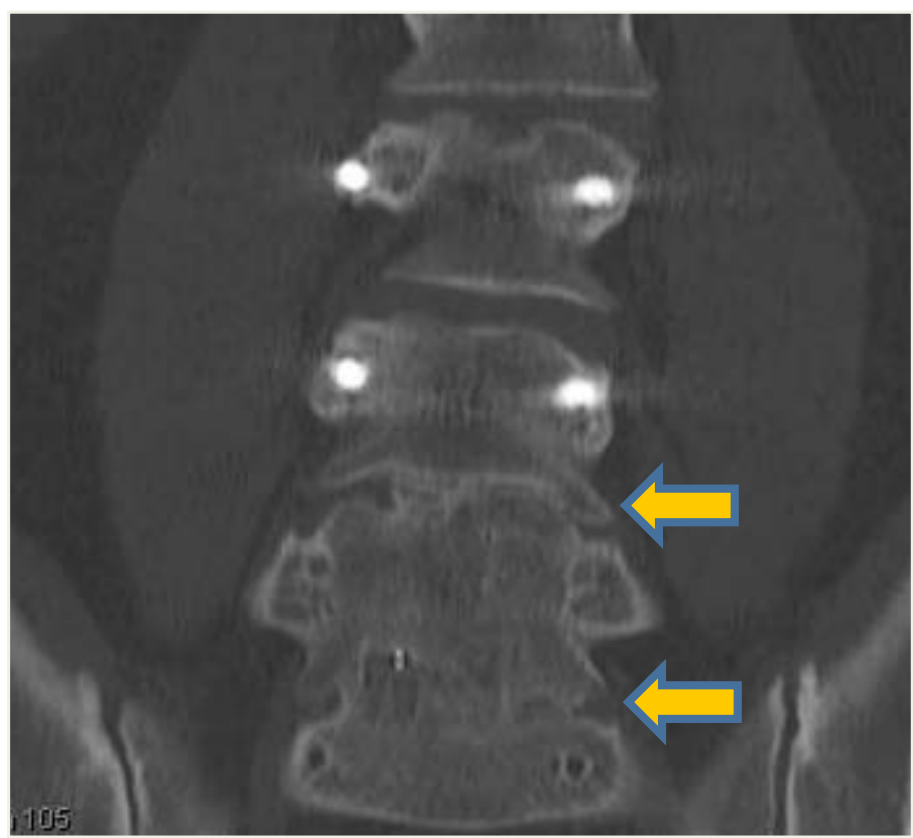

D

Fig. (1). Sagittal (A, C) and coronal (B, D) CT images at 9 months (A, B) and 16 months (C, D) post-op in a 54-year-old male who underwent 2-level posterior lumbar interbody fusion at L4-S1 (yellow arrows). The patient complained of low back pain and left buttock pain after failed previous fusion at L5-S1. Nine-month imaging demonstrates progression to fusion (A, B), with complete fusion realized by 16month imaging at the time fusion was extended to include L2-L4 (C, D). Low back pain and radiculopathy resolved following re-operation.

Successful fusion was observed in 31 of $36(86.1 \%)$ of patients (one patient in this group was lost to follow-up). Six patients $(16.7 \%)$ were deemed to have progression toward or partial fusion while $25(69.4 \%)$ were classified as stable or complete fusion. Non-fusion was observed in $5(13.9 \%)$ patients. The mean time to fusion was 9.5 months $( \pm 3.9)$.

The use of DBM in two-level fusions was not associated with better success rates. Patients where DBM was utilized 
Table 4. Final follow-up observed fusion rates based on number of levels fused.

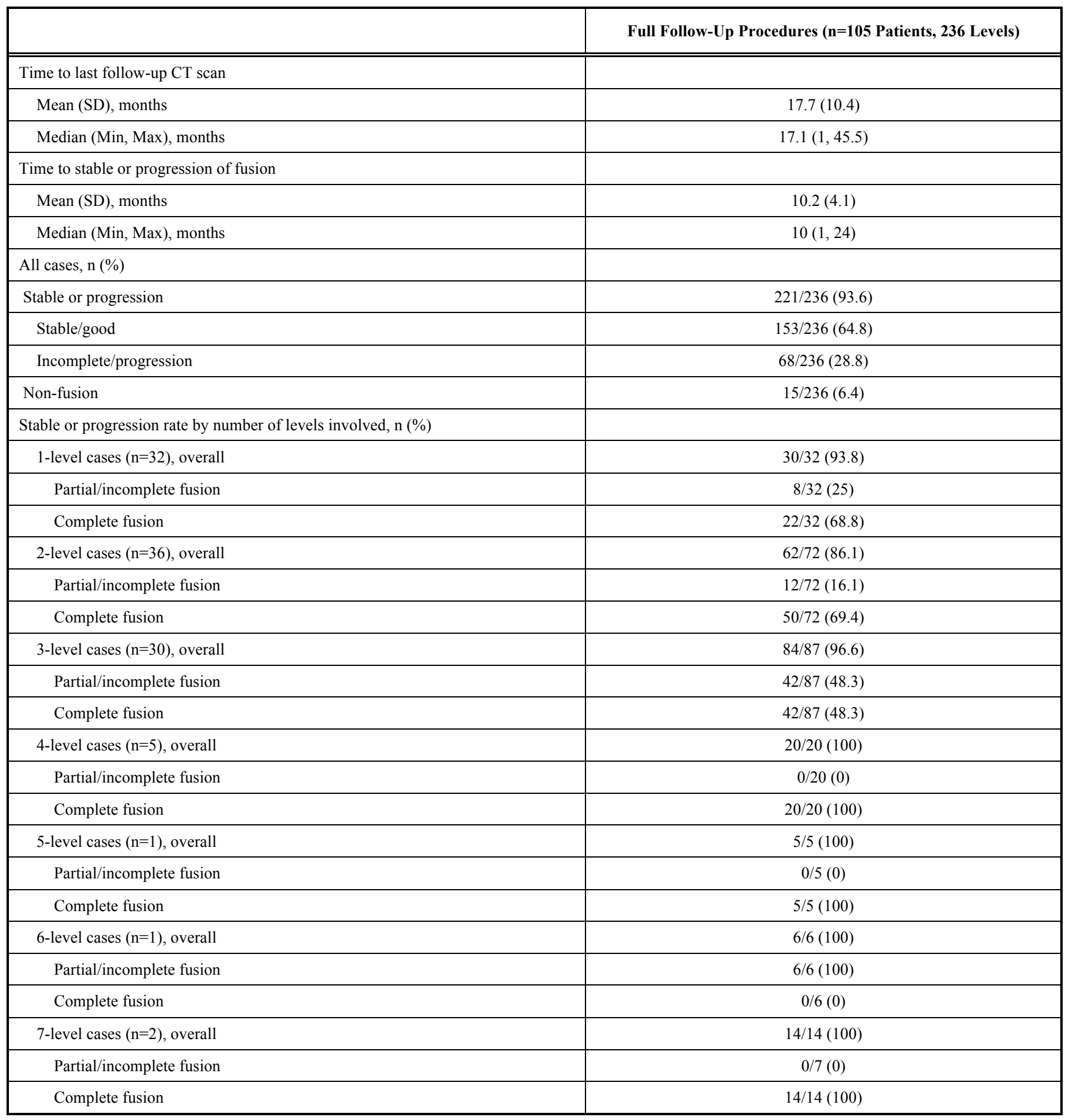

showed an $86 \%$ overall success rate (4/22 (18\%) partial fusion and 15/22 (68\%) complete fusion), while cases not using DBM showed an $85 \%$ overall success rate $(2 / 14(14 \%)$ partial fusion and 10/14 (71\%) complete fusion).

\section{Multi-Level Fusion}

Fusion at greater than 2 levels occurred in 40 patients (see Table 2). The majority of patients were fused at 3 levels $(30 / 40,75 \%)$, with 10 additional patients undergoing fusion at greater than 3 levels. The mean age of this group was 63.7 yrs $( \pm 10.1)$. Mean blood loss was $426 \mathrm{~mL}( \pm 245)$; mean LOS was 4.9 days $( \pm 2.6)$; and mean BMI was $31.9( \pm 6.4)$.

Two patients in this group were lost to follow-up and had no final fusion status. In the remaining 38 patients, fusion was deemed successful in $37(97.4 \%)$. Only 1 patient $(2.6 \%)$ was categorized as not fused. Of the successful fusion patients, $15(39.5 \%)$ were observed to have progression toward or partial fusion, while $22(57.9 \%)$ were categorized as stable or complete fusion. The mean time to fusion was 10.4 months $( \pm 4.4)$. 
Table 5. Fusion success rates, based on fused level, for cases utilizing DBM and those not utilizing DBM.

\begin{tabular}{|c|c|c|c|c|}
\hline & \multicolumn{2}{|c|}{ DBM (122 Levels) } & \multicolumn{2}{|c|}{ Non-DBM (114 Levels) } \\
\hline & Overall Success $^{1}$ Rate, n (\%) & Detailed Fusion Rates, n (\%) & Overall Success Rate, n (\%) & Detailed Fusion Rates, n (\%) \\
\hline Single-level fusion & $14 / 14(100)$ & $\begin{array}{c}\text { No fusion: 0/14 (0) } \\
\text { Partial: 3/14 (21) } \\
\text { Complete: 11/14 (79) }\end{array}$ & $16 / 18(87)$ & $\begin{array}{l}\text { No fusion: } 2 / 18(13) \\
\text { Partial: 5/18 (27.8) } \\
\text { Complete: } 11 / 18(61)\end{array}$ \\
\hline Two-level fusion & $38 / 44(86.4)$ & $\begin{array}{l}\text { No fusion: 6/44 (13.6) } \\
\text { Partial: 8/44 (18.2) } \\
\text { Complete: } 30 / 44(68.2)\end{array}$ & $24 / 28(85.7)$ & $\begin{array}{l}\text { No fusion: 4/28 (14.3) } \\
\text { Partial: 4/28 (14.3) } \\
\text { Complete: } 20 / 28(71.4)\end{array}$ \\
\hline Multi-level fusion & $64 / 64(100)$ & $\begin{array}{c}\text { No fusion: 0/64 (0) } \\
\text { Partial: } 27 / 64(42.2) \\
\text { Complete: } 37 / 64(57.8)\end{array}$ & $65 / 68(95.6)$ & $\begin{array}{c}\text { No fusion: } 3 / 68(4.4) \\
\text { Partial: } 21 / 68(30.9) \\
\text { Complete: 44/68 (64.7) }\end{array}$ \\
\hline
\end{tabular}

${ }^{1}$ Overall success defined as patient achieving partial or complete fusion at final follow-up.

DBM: demineralized bone matrix.

Fusion at three levels was performed in 29 patients, of whom $96.6 \%$ (28) had partial or complete fusion. Four-level fusion occurred in 6 patients, 1 of whom was lost to followup. Of the remaining 5 patients, all demonstrated partial or complete fusion at the final follow-up. Five- and six-level fusion was performed in 1 patient each while 2 patients underwent seven-level fusion. At the final follow-up, the patients undergoing 5- and 7-level fusion demonstrated complete fusion while the patient who underwent 6-level fusion demonstrated partial fusion.

The use of DBM had no effect on fusion rate in multilevel fusion cases. The overall success rate for fusion in the nine cases where greater than two levels were fused was $100 \%$ in all but one case, which demonstrated a $94 \%$ success rate with no DBM at 3-levels.

\section{Patient-Reported Pain}

Mean pain scores $(+\mathrm{SD})$, as measured by VAS, improved significantly both immediately post-surgery and at 12-month follow-up. Overall, there was a statistically significant decrease in VAS both immediately post-operatively $(6.8+2.5$ vs $3.1+2.9, \quad \mathrm{p}<0.001)$ and 12 -months post-operatively $(6.8+2 . \overline{5}$ vs $3.6 \pm 2.9, \mathrm{p}<0.001)$, when compared with baseline VAS. Immediately post-surgery, $70.0 \%$ of all patients had realized a MCID in VAS scores. This improvement was consistent across all patients, regardless of the number of operative levels. Detailed patient responder rates are summarized in Table 6.

\section{Adverse Events and Re-Interventions}

No complications arising from the specific use of the hybrid interwoven biosynthetic bone extender were recorded in any of the 109 cases. Furthermore, no seromas and no heterotopic bone formation were observed. Re-operations performed during the follow-up period are summarized in Table 7. Procedural complications requiring medical attention and/or return to surgery included one patient seen for superficial infection at 3 months who was treated and released. Two additional patients developed hematoma and were treated immediately without neurologic sequelae. No cases of subsidence were reported. In addition, over the course of the follow-up period, 12 re-interventions were performed for hardware removal or replacement, and 9 patients required an extension of their surgical construct due to progressive degeneration of the spine.

Of the 39 patients who reported to be working prior to surgery, 56\% (22/39) successfully returned to work.

\section{DISCUSSION}

The objective of this retrospective review was to investigate the safety and clinical effectiveness of InQu, a novel biosynthetic osteoconductive scaffold used as a local autograft extender in PLIF with supplemental instrumentation. This retrospective case series with radiologic assessment of fusion comprised 109 cases in 108 subjects at 245 individual lumbar spine levels. Local bone harvested during the decompression

Table 6. Pain severity responder rates.

\begin{tabular}{|c|c|c|c|c|c|}
\hline & $\begin{array}{c}\text { Pre-op VAS, } \\
\text { Mean (SD) }\end{array}$ & $\begin{array}{c}\text { Post-op VAS, } \\
\text { Mean (SD) }\end{array}$ & $\begin{array}{c}\text { 12-Month Post-Op } \\
\text { VAS, Mean (SD) }\end{array}$ & $\begin{array}{c}\text { Patients Achieving } \\
\text { MCID Immediately Post-Op, n (\%) }\end{array}$ & $\begin{array}{c}\text { Patients Achieving } \\
\text { MCID 12-Months Post-Op, n (\%) }\end{array}$ \\
\hline \hline All patients & $6.8(2.5)$ & $3.1(3.0)$ & $3.6(2.9)$ & $63 / 90(70.0)$ & $36 / 54(66.7)$ \\
\hline Single-level & $6.6(2.8)$ & $2.8(3.1)$ & $2.7(3.1)$ & $18 / 26(69.2)$ & $10 / 15(66.7)$ \\
\hline Two-level & $6.1(2.6)$ & $2.6(3.0)$ & $3.2(2.5)$ & $18 / 26(69.2)$ & $12 / 18(66.7)$ \\
\hline Multi-level & $7.6(1.8)$ & $3.8(2.9)$ & $4.8(3.0)$ & $23 / 33(69.7)$ & $12 / 18(66.7)$ \\
\hline
\end{tabular}

${ }^{1} \mathrm{p}<0.001$ for all pre-op $v s$ post-op comparisons.

Pre-op: pre-operative.

Post-op: post-operative.

VAS: visual analog scale.

MCID: minimally clinically important difference. 
procedure was combined with the hybrid interwoven biosynthetic bone extender and this mixture was hydrated with concentrated bone marrow harvested from the posterior iliac crest. Posterolateral fusion was then achieved utilizing the same grafting materials placed within the interbody (IB) device and into the disc space.

Table 7. Post-procedural re-operations.

\begin{tabular}{|c|c|}
\hline Type of Events & Number of Events \\
\hline \hline Hardware removal/replacement & 12 \\
\hline Extension of construct to adjacent levels & 9 \\
\hline Laminectomy, foraminotomy and/or decompression & 3 \\
\hline Hematoma & 2 \\
\hline Adjacent level decompression & 2 \\
\hline Failure & 1 \\
\hline Infection & 1 \\
\hline Augmented fusion & 1 \\
\hline
\end{tabular}

The new hybrid interwoven biosynthetic bone extender appears to safely support bone formation when applied to the axial skeleton. A total of $64.8 \%$ of the 245 individual vertebral levels demonstrated complete and stable fusion at final followup, with an additional $28.8 \%$ of vertebral levels demonstrating progression toward fusion. Thus, a total of 221 of 236 vertebral levels $(93.6 \%)$ fulfilled the success criteria for fusion, while only 15 of 236 levels $(6.4 \%)$ showed lack of fusion at final follow-up. The mean time to fusion was an acceptable 10.2 months. No safety concerns were raised with use of the product, including the lack of heterotopic ossification. There were no reported cases of implant failure, deep wound infection or seroma formation post-surgery. No loosening or failure of the hardware was noted.

While technically more difficult and typically associated with greater complication rates than anterior lumbar interbody fusion (ALIF) and transforaminal lumbar interbody fusion (TLIF) procedures [24-26], the PLIF procedure - first pioneered in the 1950s [27-29] - is associated with high fusion rates, which has resulted in its remaining a staple of lumbar fusion. The current case series demonstrated satisfactory fusion rates in patients necessitating mechanical stabilization of single, double and multiple levels without neurological complication. Previous reports have suggested that the use of local bone in cases of multiple level fusion is associated with poor fusion outcomes, necessitating the use of iliac bone grafts $[1,30]$. The current study, however, demonstrates successful fusion in 37 of 38 patients undergoing fusion at 3 or more levels (representing 129 of 132 levels). This indicates that the use of local bone in multilevel fusion is feasible when combined with an extender such as InQu. These data complement previous studies that have shown similar levels of fusion success when utilizing local bone. Coutour et al. [31] utilized the HYDROSORB bio-absorbable implant packed with locally harvested autograft and segmental internal fixation in a group of 27 patients undergoing PLIF and showed comparable efficacy, with $95.5 \%$ (42 of 44) of vertebral levels demonstrating successful fusion. They noted, however, that the rate of fusion was inversely proportional to the number of levels being fused, whereas we observed a nearly equivalent rate of fusion in single-, double- and multi-level fusion cases.

The fusion rates demonstrated in this report are comparable to those observed with the use of other bone graft extenders and fusion performed without BGE. Fusion rates above $85 \%$ at 2 to 3 years post-procedure have been demonstrated for both local and iliac crest bone grafts $[12,32]$. Synthetic BGEs have been associated with similar rates of fusion success, with one recent systematic review [7] reporting an $86.4 \%$ fusion rate when ceramic materials were utilized as the BGE, while another systematic review [13] found pooled fusion rates ranged from $75 \%$ with calcium sulphate to $98.2 \%$ with a combination of hydroxyapatite and tricalcium phosphate. The current study included supplemental posterolateral fusion for which greater quantities of bone graft are required. Despite the finite volume of autograft that could be harvested locally, concentrated bone marrow aspirate combined with cancellous allograft and biosynthetic extender appeared to provided adequate osteogenic and osteoconductive support of new bone growth.

In conclusion, the clinical experience of a single clinical site in a 109 case series of subjects requiring PLIF procedures using a fully-resorbable osteoconductive scaffold made of PLGA with integrated hyaluronic acid demonstrates that this biosynthetic bone graft extender provides good to excellent radiographic outcomes in approximately $94 \%$ of patients. Most importantly, this study demonstrates that the use of the InQu extender allows for the use of local bone and resulted in a $97.7 \%$ fusion rate in 38 patients undergoing multiple level $(\geq 3)$ fusion. Additional prospective studies evaluating its clinical success for one- and two-level transforaminal lumbar interbody fusion procedures will add to these clinical findings.

\section{ABBREVIATIONS}

$\begin{array}{ll}\text { ALIF } & =\text { Anterior lumbar interbody fusion } \\ \text { ANOVA } & =\text { Analysis of variance } \\ \text { BGE } & =\text { Bone graft extender } \\ \text { BMI } & =\text { Body mass index } \\ \text { cBMA } & =\text { Concentrated bone marrow aspirate } \\ \text { CT } & =\text { Computed tomography } \\ \text { DBM } & =\text { Demineralized bone matrix } \\ \text { IB } & =\text { Interbody } \\ \text { IRB } & =\text { Institutional Review Board } \\ \text { LOS } & =\text { Length of stay } \\ \text { MCID } & =\text { Minimal clinically important difference } \\ \text { PLGA } & =\text { Poly(D,L-lactide-co-glycolide }) \\ \text { PLIF } & =\text { Posterior lumbar interbody fusion } \\ \text { SD } & =\text { Standard deviation } \\ \text { TLIF } & =\text { Transforaminal lumbar interbody fusion } \\ \text { VAS } & =\text { Visual analog scale }\end{array}$




\section{CONFLICT OF INTEREST}

Jeffrey M. Muir and Jon E. Block received financial support from Henry Ford Health System (Detroit, MI) to assist with the preparation of this manuscript.

\section{ACKNOWLEDGEMENTS}

Henry Ford Health System (Detroit, MI) received financial support from ISTO in form of a grant to review clinical outcomes.

\section{REFERENCES}

[1] Sengupta DK, Truumees E, Patel CK, et al. Outcome of local bone versus autogenous iliac crest bone graft in the instrumented posterolateral fusion of the lumbar spine. Spine 2006; 31(9): 985-91.

[2] Dimar JR 2 ${ }^{\text {nd }}$, Glassman SD, Burkus JK, Pryor PW, Hardacker JW, Carreon LY. Two-year fusion and clinical outcomes in 224 patients treated with a single-level instrumented posterolateral fusion with iliac crest bone graft. Spine J 2009; 9(11): 880-5.

[3] Kurz LT, Garfin SR, Booth RE Jr. Harvesting autogenous iliac bone grafts. A review of complications and techniques. Spine 1989; 14(12): 1324-31.

[4] Summers BN, Eisenstein SM. Donor site pain from the ilium. A complication of lumbar spine fusion. J Bone Joint Surg Br 1989; 71(4): 677-80.

[5] Russell JL, Block JE. Surgical harvesting of bone graft from the ilium: point of view. Med Hypotheses 2000; 55(6): 474-9.

[6] Ito Z, Imagama S, Kanemura T, et al. Bone union rate with autologous iliac bone versus local bone graft in posterior lumbar interbody fusion (PLIF): a multicenter study. Eur Spine J 2013; 22(5): 1158-63.

[7] Nickoli MS, Hsu WK. Ceramic-based bone grafts as a bone grafts extender for lumbar spine arthrodesis: a systematic review. Global Spine J 2014; 4(3): 211-6,

[8] Kaiser MG, Groff MW, Watters WC $3^{\text {rd }}$, et al. Guideline update for the performance of fusion procedures for degenerative disease of the lumbar spine. Part 16: bone graft extenders and substitutes as an adjunct for lumbar fusion. J Neurosurg Spine 2014; 21(1): 106-32.

[9] Tilkeridis K, Touzopoulos P, Ververidis A, Christodoulou S, Kazakos $\mathrm{K}$, Drosos GI. Use of demineralized bone matrix in spinal fusion. World J Orthop 2014; 5(1): 30-7.

[10] Aghdasi B, Montgomery SR, Daubs MD, Wang JC. A review of demineralized bone matrices for spinal fusion: the evidence for efficacy. Surgeon 2013; 11(1): 39-48.

[11] Coseo NM, Saldua N, Harrop J. Current use of biologic graft extenders for spinal fusion. J Neurosurg Sci 2012; 56(3): 203-7.

[12] Ohtori S, Suzuki M, Koshi T, et al. Single-level instrumented posterolateral fusion of the lumbar spine with a local bone graft versus an iliac crest bone graft: a prospective, randomized study with a 2-year follow-up. Eur Spine J 2011; 20(4): 635-9.

[13] Alsaleh KA, Tougas CA, Roffey DM, Wai EK. Osteoconductive bone graft extenders in posterolateral thoracolumbar spinal fusion: a systematic review. Spine 2012; 37(16): E993-1000.

[14] Adkisson HD LL, Alvarez U, et al. Accelerated bone and cartilage repair using a novel biomaterial scaffold. $53^{\text {rd }}$ Annual Meeting Orthop Res Soc2007.

[15] Walsh WR OR, Gage G, Yu Y, Bell D, Bellemore J, Adkisson HD. Application of resorbable poly(lactide-co-glycolide) with entangled hyaluronic acid as an autograft extender for posterolateral intertransverse lumbar fusion in rabbits. Tissue Eng Part A 2011; 17: 213-9.

[16] Nade S, Armstrong L, McCartney E, Baggaley B. Osteogenesis after bone and bone marrow transplantation. The ability of ceramic materials to sustain osteogenesis from transplanted bone marrow cells: preliminary studies. Clin Orthop Relat Res 1983; (181): 255-63.

[17] Gallagher EJ, Liebman M, Bijur PE. Prospective validation of clinically important changes in pain severity measured on a visual analog scale. Ann Emerg Med 2001; 38(6): 633-8.

[18] Lee JS, Hobden E, Stiell IG, Wells GA. Clinically important change in the visual analog scale after adequate pain control. Acad Emerg Med 2003; 10(10): 1128-30.

[19] Parker SL, Adogwa O, Mendenhall SK, et al. Determination of minimum clinically important difference (MCID) in pain, disability, and quality of life after revision fusion for symptomatic pseudoarthrosis. Spine J 2012; 12(12): 1122-8.

[20] Parker SL, Adogwa O, Paul AR, et al. Utility of minimum clinically important difference in assessing pain, disability, and health state after transforaminal lumbar interbody fusion for degenerative lumbar spondylolisthesis. J Neurosurg Spine 2011; 14(5): 598-604

[21] Parker SL, Mendenhall SK, Shau D, et al. Determination of minimum clinically important difference in pain, disability, and quality of life after extension of fusion for adjacent-segment disease. J Neurosurg Spine 2012; 16(1): 61-7.

[22] Parker SL, Mendenhall SK, Shau DN, et al. Minimum clinically important difference in pain, disability, and quality of life after neural decompression and fusion for same-level recurrent lumbar stenosis: understanding clinical versus statistical significance. J Neurosurg Spine 2012; 16(5): 471-8

[23] Wang G YH. Nonunion of Osteoporotic Vertebral Fractures: Clinical Characteristics and Surgical Treatment, Spine Surgery. Chung DKJ, Ed. InTech 2012.

[24] Hee HT, Castro FP Jr, Majd ME, Holt RT, Myers L. Anterior/posterior lumbar fusion versus transforaminal lumbar interbody fusion: analysis of complications and predictive factors. J Spinal Disord 2001; 14(6): $533-40$.

[25] Humphreys SC, Hodges SD, Patwardhan AG, Eck JC, Murphy RB, Covington LA. Comparison of posterior and transforaminal approaches to lumbar interbody fusion. Spine 2001; 26(5): 567-71.

[26] Villavicencio AT, Burneikiene S, Bulsara KR, Thramann JJ. Perioperative complications in transforaminal lumbar interbody fusion versus anterior-posterior reconstruction for lumbar disc degeneration and instability. J Spinal Disord Tech 2006; 19(2): 92-7.

[27] Cloward RB. The treatment of ruptured lumbar intervertebral discs by vertebral body fusion. I. Indications, operative technique, after care. J Neurosurg 1953; 10(2): 154-68.

[28] Briggs H MP. Chip fusion of the low back following exploration of the spinal canal. J Bone Joint Surg 1944; 26: 125-30.

[29] Jaslow I. Intracorporeal bone graft in spinal fusion after disc removal. Surg Gynecol Obstet 1946; 82: 215-22.

[30] Dai LY, Jiang LS. Single-level instrumented posterolateral fusion of lumbar spine with beta-tricalcium phosphate versus autograft: a prospective, randomized study with 3-year follow-up. Spine 2008; 33(12): 1299-304.

[31] Couture DE, Branch CL, Jr. Posterior lumbar interbody fusion with bioabsorbable spacers and local autograft in a series of 27 patients. Neurosurg Focus 2004; 16(3): E8.

[32] Schizas C, Triantafyllopoulos D, Kosmopoulos V, Stafylas K. Impact of iliac crest bone graft harvesting on fusion rates and postoperative pain during instrumented posterolateral lumbar fusion. Int Orthop 2009; 33(1): 187-9. 